\title{
CULTURA E PATRIMÔNIO HISTÓRICO. ESTRATÉGIAS DE PRESERVAÇÃO E REABILITAÇÃO DA PAISAGEM URBANA E DE CENTROS HISTÓRICOS LATINO-AMERICANOS
}

\author{
Sandra de Cássia Araújo Pelegrini*
}

\begin{abstract}
RESUMEN: El presente artículo nos aproxima a la discusión acerca de la rehabilitación de los centros históricos en América Latina al hacer un análisis comparativo entre la rehabilitación del patrimonio cultural histórico de las ciudades de Olinda (Brasil) y Quito (Ecuador). De tal modo, se dedica al estudio de cartas internacionales de patrimonio histórico y al análisis de las experiencias realizadas en dichas ciudades. En este sentido, se puntualizan algunas características constructivas de los respectivos conjuntos arquitectónicos mostrando los resultados positivos de las intervenciones en el campo del turismo y la restauración de bienes culturales. El estudio concluye que las estrategias adoptadas para la rehabilitación del patrimonio cultural histórico en estos sectores se regularon por la implantación de proyectos de conservación integrada - una acción capaz de garantizar no sólo la preservación de los monumentos y los sistemas urbanos sino, principalmente, de afianzar la sustentabilidad de los centros históricos latinoamericanos - y para promover la integración de las poblaciones locales a través de la democratización del uso de los bienes culturales.
\end{abstract}

Palabras ClaVe: Paisaje urbano, Rehabilitación, Poblaciones, Sitio histórico, Bienes culturales.

A reabilitação dos centros históricos de vários países da América Latina tem chamado a atenção de especialistas nas áreas de gestão urbana, defesa do patrimônio histórico-cultural e urbanização. Tal interesse se explica, em parte, pelo êxito do desenvolvimento regional resultante da conju-

* Departamento de História da Universidade Estadual de Maringá, Paraná, Brasil (spelegrini@wnet.com.br). 
gação entre as atividades turísticas e a reabilitação de centros históricos condenados à ruína. Experiências positivas no sentido da promoção de políticas públicas no campo do turismo e da restauração de bens culturais têm se tornado uma estratégia salutar para garantir não só a preservação de monumentos e conjuntos urbanos, mas, principalmente, para afiançar a sustentabilidade dos centros históricos latino-americanos. A integração simultânea dessas duas áreas, além de conquistar a admiração de turistas estrangeiros e nacionais, contribui para reafirmar códigos visuais caros às identidades cívicas e patrióticas dos seus respectivos países. Além disso, a adequada restauração desses centros acaba integrando a população residente ao "legado vivo" da história do seu país, cidade ou região.

Deve-se reconhecer que os empreendimentos turísticos desenvolvidos na Europa, por exemplo, são tributários diretos ou indiretos da salvaguarda de parte significativa de seu patrimônio cultural, outrora condenado à irremediável destruição do tempo e à supressão da memória social. Por outro lado, assim como os bens patrimoniais assumem importante papel na promoção do turismo, logicamente, as intervenções acionadas pelo setor devem pautar-se por processos de habilitação caracterizados por técnicas especializadas de restauração e práticas democráticas de preservação, portanto, não excludentes da população originalmente residente nessas áreas.

A “Conferência das Nações” realizada em Roma (1963) já apontava a importância da tessitura política e dos investimentos no campo do turismo cultural, histórico e natural das nações, recomendando que isso se fizesse através do reconhecimento do valor cultural desses bens e da adoção de medidas dirigidas a "assegurar a conservação e a proteção desse patrimônio" (relatório de fechamento Doc. 4- SÉRIE QUITO, 1990). Desde longa data a Secretaria Geral da UNESCO vem solicitando estudos acerca da viabilidade de se promover organizações oficiais de turismo capazes de fomentar políticas de intervenção que garantam a sustentabilidade econômica.

No âmbito dessas iniciativas, recomendações tem incitado a preservação de monumentos e outros bens culturais de natureza arqueológica, 
artística e histórica, tanto na esfera nacional como na regional. Nesse sentido, cada vez mais, vêm sendo valorizadas as realizações capazes de fomentar simultaneamente, a vocação turística à preservação e, uso do patrimônio monumental e artístico das cidades latino-americanas.

Do ponto de vista exclusivamente turístico, os monumentos, produções culturais e bens naturais são considerados partes integrantes do "equipamento urbano" que, se devidamente preservados, podem concorrer para o desenvolvimento das cidades. Entretanto, para se alcançar tal êxito faz-se necessário o traçado de planos correspondentes entre as duas áreas:

[...] los intereses propiamente culturales y los de índole turística se conjugan en cuanto concierne a la debida preservación y utilización del patrimonio monumental y artístico de los pueblos de América. ${ }^{1}$

Assim, não se pode ignorar a relevante promoção de investigações acerca dos Programas de Reabilitação de Centros Históricos, como aquele acionado em Histórico de Quito (822/OC-EC) — aprovado em setembro de 1994, orçado em cerca de US\$51,3 milhões de dólares, e cuja proposta sugeria a preservação e a reabilitação dessa área por meio da reativação de sua funcionalidade. A revitalização das atividades comerciais e dos serviços tradicionais certamente contribuiu para facilitar o acesso aos bens e serviços oferecidos pelo local.

Desse modo, o projeto visava promover o uso correto e a manutenção dos edifícios públicos e privados, tornando-os mais atrativos para os visitantes e para a própria população residente. Este programa incluiu a reabilitação de edifícios históricos, o melhoramento dos arredores das instalações urbanas e sinalização, construção de cinco estacionamentos para veículos, estabelecimento de um Fundo de Reabilitação, criação de

${ }^{1}$ SÉRIE QUITO. Centro Histórico de Quito. Problemática e Perpectivas, Quito, Dirección de Planificación/Municipio de Quito. C. Obras Públicas y Transporte/ Ministerio de Asuntos Exteriores de España, 1990. 
uma empresa mista que promovesse o investimento privado no centro histórico, fortalecendo o executor do técnico do programa, qual seja, a própria Prefeitura Municipal de Quito.

Assim, também perspectivava estimular programas de turismo, a reabilitação urbana e a conservação histórica, políticas e ações capazes de refrear a deterioração do território urbano, normalizando e limitando a circulação de veículos, a contaminação ambiental, aglomeração e ocupação indiscriminada, criminalidade. Por fim, o fortalecimento institucional da municipalidade auxiliaria o desenvolvimento da sua capacidade gerencial e financeira de estudos completares sobre possíveis sistemas de controle da contaminação atmosférica.

Essa proposta apresenta certas similaridades com as propostas de conservação urbana integrada apresentadas adotada em meados dos anos setenta, pelo Conselho da Europa, como uma diretriz fundamental para o planejamento urbano dos centros históricos do continente. No ano de 1975, o mesmo Conselho, reunido em Amsterdã, formulou a "Declaração de Amsterdã” sistematizando algumas orientações para viabilizar a implantação da Conservação integrada, norteada por princípios que deveriam ser acionados especialmente para o poder público municipal. ${ }^{2}$

As intervenções sugeridas no referido documento, segundo Silvio Mendes Zancheti, "não apresentam uma definição clara do conceito de conservação integrada, mas a adotam como uma abordagem ou um modo de conceber e orientar a ação de intervenção em áreas urbanas históri-

2 A conservação urbana integrada, segundo Sílvio Mendes Zancheti (1995) tem origem no urbanismo reformista italiano dos anos 1960/70, mais especificamente, na experiência de reabilitação do centro histórico da cidade de Bolonha, iniciada nos últimos anos da década de 60, e conduzida por políticos, administradores, planejadores e arquitetos ligados ao Partido Comunista Italiano. Planejadores como Campos Venuti, Benevollo e Cervellati ganharam notoriedade mundial por suas originais contribuições no campo do planejamento urbano e da conservação patrimonial das cidades. Cfr. Sílvio Mendes Zancheti, Geraldo Marinho e Vera Millet [org.], Estratégias de intervenção em áreas históricas —revalorização de áreas urbanas centrais, Recife, MDU/UFPE, 1995. 
cas", tributário do planejamento conjugado entre a cidade contemporânea e o espaço urbano patrimonial prevendo a sua utilização, segundo novos usos e necessidades sociais. ${ }^{3}$

Distanciando-se um pouco dessa forma de abordagem sobre a conservação integrada, posteriormente, estudiosos do espaço urbano iriam propor que os modos de "conservação, restauração e reabilitação de edifícios e sítios antigos" deveriam pautar-se por sua "readaptação às novas funções da vida moderna". ${ }^{4}$ Aprimorando a assertiva de Choay, J. Jokilehto sugeria que a "conservação integrada seria plenamente alcançada desde que as técnicas de restauração se norteassem pela escolha correta de funções apropriadas no contexto de áreas históricas, levando em conta a pluralidade de valores, tanto econômicos como culturais." 5

Se, nos anos 70 e 80, ambos sugeriam a adaptação de edifícios antigos aos usos contemporâneos, mantendo-se as características originais dos imóveis restaurados e a reutilização do seu valor patrimonial, nos anos 90, outras interpretações iriam versar sobre relação a preservação — integração - patrimônio histórico, inspiradas nos paradigmas do planejamento, em especial, na do desenvolvimento sustentável.

A "conservação integrada" assentava-se num modo de abordar o planejamento e a gestão do patrimônio cultural urbano, mediante ampla integração nas políticas de gestão e práticas econômica, política, cultural, ambiental e físico-espacial multidimensionais, sem, no entanto, comprometer a autenticidade do patrimônio cultural. Desse modo, a conservação integrada deve buscar o desenvolvimento sustentável, inserindo a conservação do patrimônio-cultural urbano no âmbito de políticas e ações

\section{Ibid.}

${ }^{4}$ Françoise Choay, "O reino do urbano e a morte da cidade", Projeto História, no. 18, São Paulo, mai, 1999.

${ }_{5}$ Jukka Jokilehto e Bernard M. Feilden, Manual para el manejo de los sitios del patrimonio mundial cultural, Bogotá, Instituto Colombiano de Cultura/Colcultura, 1995. 
capazes de promover o desenvolvimento regional em todas as suas dimensões.

Assim, tornam-se relevantes os estudos dos conjuntos arquitetônicos que realizem investigações acerca da história dos projetos construtivos e das técnicas utilizadas na sua execução, de modo a propiciar o contato com valores, hábitos, manifestações religiosas, adaptações ao meio sócio-ambiental, além de diversos outros fatores que caracterizam os bens culturais e o patrimônio histórico de uma sociedade. Esse enfoque tornase ainda mais pertinente quando nos ocupamos das transformações ambientais do espaço urbano e das alterações de natureza estética e funcional processadas nos projetos arquitetônicos das habitações das mais diversas áreas do continente latino-americanas, principalmente entre os períodos que marcaram o início da colonização até o decorrer do século XIX.

Nesses termos, a abordagem proposta não pode se furtar a enfrentar as questões que envolvem a política de preservação dos monumentos históricos, pois no Continente Americano, especialmente no Brasil, a legislação que inicialmente se ocupou dessa matéria alicerçou-se na observância da função social da propriedade, ${ }^{6}$ aspecto que, por sua vez, acabou implicando a conservação de bens móveis e imóveis considerados memoráveis para história do país e relegou outros bens culturais ao esquecimento. Na esfera arquitetônica, tal definição se prestou a justificar, por um lado, a conservação de residências de segmentos dominantes, por outro, o descaso em relação à preservação de edifícios menos sofisticados e casas populares, identificados até mesmo como entraves para a modernização.

\footnotetext{
${ }^{6}$ A questão do patrimônio nacional se inscreveu ao princípio constitucional, em 1934. A primeira lei nacional de proteção ao patrimônio foi promulgada através do Decreto-lei n. ${ }^{\circ}$ 25, de 30 de 11 de 1937. Cfr. Maria Clementina Pereira Cunha [org.], $O$ Direito à memória. Patrimônio Histórico e Cidadania, São Paulo, Dep. do Patrimônio Histórico/Secretaria Municipal de Cultura/Prefeitura de São Paulo, 1992. Consultar também IPHAN. Legislação Brasileira de Proteção aos Bens Culturais, Ministério da Educação e Cultura, 1976.
} 
A implementação de leis voltadas para a defesa do Patrimônio Histórico representou um avanço no campo da preservação da memória social do país, no entanto, os fundamentos que informaram essas práticas preservacionistas acabaram provocando a expropriação cultural de maior parcela da população que não se viu reconhecida em obras suntuosas como solares, casarões, igrejas, câmaras municipais, fortificações, entre outros edifícios. ${ }^{7}$

A despeito desse problema, deve-se reconhecer que uma observação mais detida acerca da singularidade construtiva das residências expressa, por exemplo, na distinção dos espaços destinados à execução de serviços, ao lazer ou convívio familiar, nos permitem vislumbrar registros de referenciais culturais que envolvem tanto os segmentos dominantes, quanto os empregados domésticos, indícios de formas de organização do trabalho e dos embates travados no âmbito dessas habitações.

As edificações públicas ou privadas, como produtos de uma dada época, constituem registros visuais dos anseios, necessidades e contradições sociais. O traçado arquitetônico e as formas de organização do espaço comportam representações do contexto socioeconômico em que emergiram. Para percebê-las faz-se necessário empreender esforços no sentido de detectar fatores físicos inerentes à produção arquitetônica, tais como: atribuições funcionais, técnicas e materiais utilizados nas obras, dificuldades de implantação dos projetos, entre outros.

Deve-se observar, por exemplo, o fato de que as construções erigidas no século XIX alteraram significativamente a paisagem urbana dos locais onde foram implantadas, embora precisassem adaptar-se aos materiais disponíveis na região e, principalmente, aos desníveis do terreno, em função das rudimentares condições técnicas de que se dispunha para realização do processo de aterro e corte da terra. Aliás, nessa época, ambos eram realizados manualmente em todo continente latino-ameri-

${ }^{7}$ Déa Ribeiro Fenelón, "Políticas Culturais e Patrimônio Histórico. In São Paulo (cidade)", O direito à memória: patrimônio histórico e cidadania, Secretaria Municipal de Cultura de São Paulo, São Paulo, DPH, 1992, p. 30. 
cano, o que tornava o processo dispendioso e demorado. ${ }^{8}$ Por outro lado, tanto no caso brasileiro, como de Quito, as condições socio-econômicas e climáticas constituíram elementos determinantes na confecção das plantas, agenciamentos e partidos arquitetônicos desenvolvidos. Esses projetos construtivos, via de regra, tiveram que ser adaptados às condições locais, sendo acrescentados a alguns dos seus ambientes internos e fachadas referenciais estéticos europeus.

A profusão de elementos plásticos de origem lusitana, francesa ou espanhola, não impediu que fossem edificadas réplicas de residências portuguesas ou versões populares de casas da Andaluzia em algumas províncias do Nordeste e do Sudeste brasileiro, nem tão-pouco, no centro urbano de Quito. Na Província de São Paulo, por exemplo, não raro se optava por projetos arquitetônicos fundamentados em princípios de simetria hispânicos evidenciados em plantas quadradas ou retangulares, corredores fronteiros e posteriores, amplos telhados de quatro águas, discretas aberturas nas janelas, alternância de "cheios e vazios" (corredores de pilares de madeira ladeados por panos de parede com uma janela em cada lado). ${ }^{9}$ Talvez, essa característica estética das residênci-

${ }^{8}$ No caso das sedes de fazenda, outro aspecto considerado era a instalação das residências em áreas próximas aos rios ou açudes da propriedade, de modo a garantir o abastecimento de água da casa e a irrigação dos campos de plantio, caso fosse necessário. Além disso, a escolha da localização das moradias atendia a vetores topográficos estratégicos, capazes de proporcionar o controle sobre o comportamento dos escravos, o trânsito de pessoas estranhas à propriedade e os trabalhos realizados na fazenda. Maria Cintra Gordinho, Casa do Pinhal, São Paulo, C.H. Knapp, 1985 e Casa de Fazenda —uma seleção de dezessete fazendas no mais puro estilo da arquitetura rural brasileira, São Paulo, Ed. Abril S. A., 1997.

${ }^{9}$ Sobre o assunto consultar de dois livros de Carlos A. Lemos: Alvenaria Burguesa: breve história da arquitetura residencial de tijolos em São Paulo a partir do ciclo econômico liderado pelo café (publicado na cidade de São Paulo, pela editora Nobel, no ano de 1985) e Historia da Casa Brasileira (publicado em São Paulo, pela editora Contexto, em 1996). Paulo César Xavier Pereira também publicou a esse respeito a obra Espaço, Técnica e Construção: o desenvolvimento das técnicas construtivas e a urbanização do morar em São Paulo, publicado na cidade de São Paulo, pela editora Nobel, em 1988. 
as brasileiras possa ser explicada pela tentativa dos imigrantes que para cá se dirigiram de preservarem valores culturais, noções do belo e do gosto europeu, e ainda, imagens que lhes pudessem garantir certa identidade com suas origens. ${ }^{10}$

Um olhar atento ao traçado dessas antigas moradias da cidade de Olinda, estado de Pernambuco (Brasil) e Quito (Equador), torna possível identificar os partidos arquitetônicos típicos dos sobrados construídos no início do século XIX. Trata-se de edifícios com dois ou três pavimentos, sacadas frontais ou varandas em rótulas que abrangem toda a fachada do segundo andar. Mas, no decorrer das primeiras décadas desse século, processaram-se mudanças substanciais nas concepções das residências urbanas e rurais no Brasil. O deslocamento da corte portuguesa para a colônia (em 1808), gerou a necessidade de reorganização do Rio de Janeiro, de modo a acomodar o recém-chegado contingente de nobres e criados. Os estudiosos do tema salientam que esse rearranjo da "cidade" desencadeou uma "onda" de novas construções. ${ }^{11}$

A arquitetura colonial marcada por excessivo despojamento e pela característica da horizontalidade, bem como da arquitetura barroca, cuja expressão monumental manifestava opulência, foram paulatinamente suplantadas pela adoção de referênciais estéticos neoclássicos. Os interiores, anteriormente adornados com um número restrito de móveis confeccionados nas próprias colônias portuguesas e espanholas, seriam incrementados pela aquisição de mobílias e objetos decorativos europeus. ${ }^{12}$

O conjunto arquitetônico, urbanístico e paisagístico da cidade de Olinda, marcado pelo casario colorido, característico do povoamento português colonial, e pela monumentalidade das igrejas alvas, seria re-

${ }^{10}$ José Wasth Rodrigues, Documentário Arquitetônico, São Paulo, Livraria Martins Editora, 1970, p. 29.

${ }^{11}$ Francisco Salvador Veríssimo, 500 anos da casa no Brasil, Rio de Janeiro, Ediouro, 1999.

12 Ebe Reale, "Evolução da casa urbana brasileira", in Revista Digesto Econômico, no. 246, ano XXXII, nov/dez, 1975, p. 108. 
conhecido pela UNESCO como patrimônio mundial, cultural e natural da humanidade, em 1982. Todavia, desde 1968 já havia sido inserido nos Livros de Tombo de Belas Artes, no Histórico e no Arqueológico, Etnográfico e Paisagístico, nos anos finais da década de sessenta (1968), uma vez que a cidade conservou o traçado urbano e a paisagem da vila fundada pelos portugueses, na primeira metade do século XVI, mais precisamente em 1537, quando Duarte Coelho Pereira ocupou essas terras.

Esse conjunto arquitetônico, integrado à paisagem natural da cidade, apresenta tanto elementos característicos do século XVII, expressos em balcões de treliça, como aspectos predominantes nas edificações erguidas nos séculos XVIII e XIX, tais como revestimentos de azulejos e outros componentes do estilo neoclássico. A arquitetura sofisticada das igrejas, no entanto, contrasta como a simplicidade do casario colorido que manifesta traços da cultura portuguesa, modificados pela necessidade de adaptação ao terreno, ao clima e aos materiais disponíveis.

As igrejas construídas, a partir do século XVI, sob os auspícios das missões religiosas, receberam partidos arquitetônicos inspirados no estilo barroco, constituíram templos repletos de pinturas minuciosamente ornamentadas, painéis de azulejos e altares detalhadamente talhados. Algumas foram implantadas em áreas com vistas privilegiadas, cercadas por jardins, coqueirais e outras árvores frutíferas distribuídas ao longo das encostas e alamedas que circunscrevem as áreas centrais.

As igrejas, capelas e passos, embora protegidas pelo patrimônio histórico, mantêm até hoje suas funções originais na esfera do culto religioso católico, de tradição colonial. A riqueza estilística de construções como a da Igreja da Sé (1537), da Igreja de Nossa Senhora da Misericórdia (1540), da Igreja de São Francisco (1577), do Mosteiro de São Bento (1582) e do Museu de Arte Sacra, localizado no antigo Palácio Episcopal (1676) favorecem o fomento do turismo cultural, do qual parte significativa da população da cidade não só participa, como se mantém identificada.

Não por acaso, as atividades turísticas movimentam a economia de Olinda, geram empregos e recursos empregados na própria conservação 
dos bens culturais e do patrimônio histórico. Os ritos religiosos, as festas e as artes populares nutrem as tradições regionais e, simultaneamente, articulam-se entre si, alimentando o respeito local pelas procissões e a preservação das danças dos pastoris e do maracatu, do frevo e do carnaval pernambucano. $\mathrm{O}$ desenvolvimento de atividades artesanais, principalmente, da talha na madeira e da cerâmica no barro, além de expressar a criatividade artística dos cidadãos olindenses, constitui importante complemento da renda familiar da população menos abastada.

Localizada em área elevada e inspirada numa ordenação mediterrânea que garantia estratégias militares de defesa, a cidade acabou se tornando sede do governo na época da colonização. Tais peculiaridades não implicaram, no entanto, o planejamento do traçado urbano, nem tampouco a proliferação de vias com formatos regulares. Muito pelo contrário, as ladeiras abruptas, vielas estreitas e irregulares foram sendo delineadas nos moldes comuns aos lugarejos povoados por portugueses, de origem medieval.

As vias urbanas que garantiam o acesso às igrejas, aos conventos e as demais edificações, na sua maioria, se formaram ora seguindo as curvas e o traçado sinuoso das encostas, ora emolduradas pelas dimensões aleatórias dos muros e fachadas do casario colorido que se ergueram continuamente no decorrer da ocupação de Olinda. Os caminhos acidentados das ruas, somados ao feitio das edificações erguidas entre as áreas do mar e das encostas recobertas por vasta vegetação, criaram a impressão de um grande labirinto repleto de cruzamentos inesperados.

Por certo, no caso brasileiro, a vinda da família real para Colônia acabou alterando a fisionomia das sedes administrativas, principalmente da cidade do Rio de Janeiro e de outras regiões próximas. Esse deslocamento incrementaria a vida cultural da população colonial, pois propiciaria o acesso a um número maior de livros e o convívio dos colonos com intelectuais, cientistas e viajantes europeus. Na esfera arquitetônica, essa relativa circulação de idéias, intensificar-se-ia com a chegada do arquiteto Grandjean de Montigny, integrante da Missão Artística Francesa ao Rio de Janeiro, em 1816. Ele seria responsável por projetos de 
edificação urbana, contribuindo para o fomento da estética neoclássica na Colônia. ${ }^{13}$

Em meados do século XIX, parte significativa das construções residenciais das colônias portuguesas e espanholas na América Latina ainda era térrea e as cozinhas mantidas longe do corpo principal da casa. Os sobrados, na região Sul e Sudeste do Brasil, normalmente, eram construídos com dois andares, enquanto que, no Nordeste, alguns edifícios atingiam três ou quatro pavimentos. Mas, curiosamente, nas cidades de Olinda e, particularmente, do Recife, foram edificados sobrados com até seis pavimentos, sendo a cozinha localizada no último andar justamente para evitar que os odores oriundos dos cozimentos se disseminassem nos outros pavimentos do edifício. ${ }^{14}$

A difusão do convívio em sociedade lentamente impulsionou mudanças no comportamento das elites, perceptíveis também na organização espacial das suas residências. As salas, anteriormente de exclusivo uso familiar, abriram-se aos visitantes. O hábito de receber suscitou o interesse pelas áreas sociais das residências e a ampliação do número de cômodos destinados à recepção. Salas com as mais diversas funções foram anexadas ao corpo da casa, surgiram salas de jogos, música e jantar, além de salões principais, destinados a jantares, festas, saraus e bailes.

Algumas casas da área rural eram monumentais, mas, geometricamente simples e decoradas com poucos adornos. No decorrer do século XIX, com o desenvolvimento das cidades, predominou a construção de

${ }^{13}$ Montigny imprimiu à arquitetura brasileira a estética neoclássica, sendo responsável pelo projeto do prédio da Academia de Belas-Artes, erguido em 1826. Um dos seus alunos, José Maria Jacinto Rebelo, projetou o Solar dos Marqueses de Itamarati que serviu posteriormente de sede ao Ministério das Relações Exteriores, com o nome de Palácio do Itamarati, durante o período em que a cidade do Rio de Janeiro foi a capital o país. Afonso Taunay, A missão artística de 1816, Brasília, Fundação Roberto Marinho/Editora da UnB, 1983. Sobre esse assunto, consultar também: Richard Grahamn, Clientelismo e Política no Brasil do século XIX, Rio de Janeiro, Ed. UFRJ, 1997.

${ }^{14}$ Reale, op. cit., p. 104. 
"palacetes" de influência notadamente européia, inspirados no estilo neoclássico e eclético. O ecletismo é o termo utilizado para denominar o movimento arquitetônico em voga na Europa a partir do final do século XVIII até o início do XX, e que predomina no Brasil a partir de meados do século XIX até as primeiras décadas do XX, devido ao intenso intercâmbio de idéias, mão-de-obra, materiais e produtos industrializados, que se dá neste período. ${ }^{15}$ Trata-se de um estilo revivalista que reúne diversas manifestações arquitetônicas numa mesma obra, e cujo efeito prima pelo aspecto decorativo. ${ }^{16}$

Em meados do século, a arquitetura urbana incorporou novas técnicas e estruturas metálicas, tais como: fachadas com prumada de pilastras sobre a platibanda, a adoção de soluções mais complexas na cobertura como telhados de quatro águas, anexação de figuras de louça do Porto e vasos, que revelaram o resultado plástico das adaptações coloniais aos modismos estéticos. ${ }^{17}$ Alterações mais substanciais seriam detectadas nos interiores das residências, nos quais a valorização do conforto evidenciaria preocupações com privacidade e higiene, enquanto que a associação entre objetos e móveis importados implicaria na distinção do design e das obras de arte como signos de opulência, cultura e gosto apurado.

Detecta-se, no último quartel da segunda metade do século XIX, a emergência de casas com porão alto — modelo considerado pelos especialistas como uma fase intermediária entre a construção dos sobrados coloniais e as casas térreas. Esse tipo de fachada foi muito comum entre os edifícios construídos na cidade de Parati, no Rio de Janeiro, que atualmente foram transformados em pousadas para turistas ou casas de veraneio. Tais construções guardaram traços da organização da família patriarcal, procurando resguardar as áreas internas da residência das vistas

${ }^{15}$ Maria Paula Albernaz, Dicionário Ilustrado de Arquitetura, São Paulo, Pró-Editores, 2000, p. 208.

${ }^{16}$ E. H. Gombrich, A história da arte, Lisboa, LTC, 1999.

${ }^{17}$ Nestor Goulart Filho Reis, Quadro da Arquitetura no Brasil, São Paulo, Perspectiva, 1970, p. 38. 
dos transeuntes. Os porões eram privados de iluminação e ventilação adequada, possibilitada somente através de pequenas aberturas denominadas "óculos", vedados com gradis de ferro .

De maneira diferenciada do caso da cidade de Olinda, Quito foi erigida em meio a cenários vulcânicos, rodeados por densa floresta, aspecto que, provavelmente, tenha contribuído para retardar por dois anos a invasão dos conquistadores espanhóis que já haviam se instalado na região desde 1532. No entanto, seus conjuntos arquitetônicos também contam com monumentos e prédios construídos sob inspiração barroca. A decoração interna da Igreja e a Faculdade Jesuíta de La Companhia, os Mosteiros de São Francisco e Santo Domingo, constituem exemplos do barroco típico da fusão entre diferentes expressões da arquitetura indígena, flamenga, moura, espanhola e italiana. Enquanto o casario e as igrejas apresentam traços típicos da arquitetura portuguesa, saltam aos olhos influências estéticas espanholas, de origem moura, erguidas em Quito, no século XVI, sobre as ruínas de uma cidade inca.

Nesses termos, a capital do Equador vem sendo apontada pelos especialistas em patrimônio histórico, como Roberto Segre, ${ }^{18}$ como uma das regiões latino-americanas que melhor preservaram seu o centro histórico, haja vista que os projetos de restauração lá desenvolvidos pautaram-se pelo resgate da tipologia das construções, tomando por fundamento a informação histórica disponível que concorreu para transformar o conjunto arquitetônico num "testemunho" urbanístico do século XIX. As intervenções realizadas nas edificações destinadas originalmente à habitação e a outros usos, durante o processo de reabilitação do Centro Histórico de Quito, privilegiaram na sua maioria as habitações, integrando as populações locais.

Mas, segundo Rolando Tasquer e Evelia Peralta, a revitalização desses ambientes e dos espaços públicos, mediante o fortalecimento da função habitacional e do equipamento coletivo, implicou numa reabili-

${ }^{18}$ Roberto Segre, "Havana: o resgate social da memória”, in Pereira Cunha, op. cit. 
tação integrada, capaz de envolver o morar e orientar a seleção dos imóveis que seriam adquiridos por organismos públicos e privados e tomados como intervenções exemplares na esfera preservação do patrimônio não excludente e da melhoria da qualidade do ambiente urbano. ${ }^{19}$

A restauração das principais moradias da rua Caldas apoiou-se na concentração de serviços, equipamento e infra-estrutura, concepção que transformou o centro histórico da cidade num espaço alternativo residencial, beneficiando-se a reativação econômica e turística do local sem comprometer o patrimônio histórico. A casa 508 constitui exemplo significativo da recuperação do valor habitacional patrimônio equatoriano comandado pelo arquiteto Luiz Lopez, que primou por preservar os parâmetros da estrutura original das casas de pátio, com todos os elementos típicos da estrutura colonial, embora tivesse que acrescer a altura total do edifício e promover outras pequenas alterações nas proporções do edifício e nos materiais empregados.

Outras restaurações coordenadas pela arquiteta Lucía Vásconez, nas ruas Caldas e Briceño também privilegiaram o resgate da tipologia das casas de pátio, preservando a função original de habitação e comércio, mas utilizando formas e materiais (como coberturas de vidros) que expressam intervenções modernas pautadas pelo restabelecimento de espaços de comunicação bem iluminados, trato do entorno e do interior dos edifícios capaz de evidenciar o uso de antigos e novos matizes de cor e tipos de materiais construtivos que conferem beleza aos ambientes e locais restaurados, possibilitando os respectivos usos social e turístico sustentável. Não obstante, a Casa dos Sete Pátios constitui um caso emblemático da reabilitação idealizada para a cidade de Quito, pois a reabilitação da tipologia desse tipo de casas restabeleceu o convívio entre numerosas famílias que a habitavam e freou o avançado estado de deterioração dos imóveis. As características da referida construção induzi-

${ }^{19}$ Rolando Tasquer e E. Peralta, "Resgate das edificações históricas para função habitacional", in Casas del Ecuador II, Quito, Ediciones Trama, s. d. 
ram os arquitetos Jorge Carvajal, Patrícia Fondello, José Román Ruiz e Emilio Yanes, responsáveis pelo projeto a preverem inclusive a necessidade de acompanhamento contínuo, no mínimo por vinte e cinco anos.

Por certo, um dos méritos mais importantes da análise do caso da preservação do patrimônio histórico-cultural de Quito, diz respeito ao amplo projeto de reabilitação do Centro Histórico de Quito, idealizado por volta de 1991, e viabilizado mediante um empréstimo junto ao BID entre 1994-1999 (inicialmente orçado em cinqüenta mil dólares). Uma proposta integrada que Paulina Burbano de Lara, diretora da Empresa do Centro Histórico de Quito, tem relatado em vários debates sobre políticas de sustentabilidade econômica dos centros históricos latino-americanos e sua consequiente revitalização cultural e turística. Nesse sentido, tem destacado que inicialmente o projeto financiado pelo BID em 1994 visava apenas reativar economicamente o local por meio da recuperação da infra-estrutura urbana (calçadas, mobiliário, sinalização na cidade) e de equipamentos urbanos como a instalação de hotéis, restaurantes, museus e edifícios de estacionamento. Mas, quatro anos e meio depois, o trabalho resultou numa efetiva melhoria da qualidade de vida da população residente e dos comerciantes informais que lá se alojavam.

Inicialmente, objetivava-se apenas a edificação de dois grandes centros comerciais e resolver a questão do trânsito, mediante o incremento do transporte coletivo (trólebus) e das ecovias, induzindo os habitantes do Centro Histórico e os turistas a não fazerem uso de veículos individuais. Entre 1994 e 1997, a cidade incorporou a construção de dois sistemas importantes de trânsito. No decorrer do desenvolvimento do projeto de reabilitação do Centro Histórico de Quito, tombado pela UNESCO, desde a década de setenta, foram detectados e catalogados como bens culturais cerca de cinco mil imóveis, onde viviam cerca de cem mil habitantes em condições habitacionais muito precárias. A partir de então, percebeu-se a necessidade de acionar um processo de recuperação patrimonial que fosse capaz de incorporar a dinâmica pertinente a um bairro residencial, com ativa vida noturna e outros tipos de atividades urbanas. 
Desse ponto de vista, propunha-se a restauração de um centro histórico heterogêneo capaz de abrigar moradores e de receber um número elevado de visitantes ou transeuntes por dia, interessados na realização de negócios, trabalhos, passeios (principalmente nas igrejas). Contudo, o centro havia sido descaracterizado da sua função residencial, as poucas habitações que ainda mantinham suas funções originais encontravam-se em sérias condições de deterioração, com possibilidades de utilização apenas dos cômodos localizados nos andares térreos para fins de refeições. O resto das casas mostrava-se completamente desabitado. A inclusão da proposta de moradia solidária, dois anos após o início do projeto, presumia a adoção de políticas públicas de desenvolvimento urbano que contemplassem amplos processos integrados de conservação urbana em perímetros de intervenção precisos, evitando-se operações dispersas que inviabilizariam a otimização da infra-estrutura instalada.

A preservação patrimonial integrada, deve-se salientar, passou a ser incorporada às políticas urbanas latino-americanas municipais apenas na década de noventa, mas promoveu a revitalização de muitos centros históricos, encampando políticas de referência, recomendadas pelas principais agências de fomento internacional de projetos de preservação patrimonial, como a do Banco Inter-Americano de Desenvolvimento (BID) e a do Banco Mundial.

Para concluir, não se pode negligenciar a importância da UNESCO continuar atenta aos apontamentos relatados pelos especialistas e pelos executores de projetos desse fôlego, manter as recomendações no sentido de que os centros históricos sejam tomados como: a) áreas culturais, testemunhas da história social e da história da arquitetura e do urbanismo que contribui para a identidade cultura do país e de seus habitantes; b) áreas de exercício social ou como locais de vida e trabalho; c) espaços geradores de atividades formais e informais vinculadas à cidade. Enfim, como territórios citadinos portadores de exemplares arquitetônicos, espaços urbanos e uso do solo que expressam modalidades do viver dos seus habitantes pretéritos e aportes estéticos do passado, parcialmente modificados pelo processo sócio-econômico e de urbaniza- 
ção contemporâneos; e finalmente, como um meio ambiente sujeito à pressão de séculos modificadores na história da cidade e da região.

$\mathrm{Na}$ verdade, as intervenções realizadas nas paisagens urbanas latino-americanas têm se tornado viáveis, graças à ação conjugada entre as políticas públicas de preservação e a empresa turística. Não se deve, nesses termos, negar as efetivas contribuições de empreendimentos como aqueles realizados nas cidades Quito (Equador) e Olinda (Brasil), projetos que privilegiaram a integração dos bens culturais à dinâmica da vida social local. Talvez mais em Quito, do que em Olinda, a reabilitação do centro histórico tenha conseguido frear a deterioração do conjunto arquitetônico, resgatando não apenas a utilização comercial e turística dos seus respectivos espaços, mas principalmente o uso habitacional tradicional —recuperando a auto-estima e a história dos seus originais habitantes. ${ }^{20}$ Nesses locais verificou-se um tipo de intervenção que não desprezou os pobres que ali residiam, muito pelo contrário, foram adotadas medidas de proteção do patrimônio histórico, mediante a democratização do uso dos bens culturais.

${ }^{20}$ SÉRIE QUITO. Centro Histórico de Quito. Sociedad e Espacio Urbano, Quito, Dirección de Planificación/Municipio de Quito. C. Obras Públicas y Transporte/ Ministerio de Asuntos Exteriores de España, 1993. 